\title{
Intraoperative Use of Epsilon Amino Caproic Acid and Tranexamic Acid in Surgeries Performed Under Cardiopulmonary Bypass: a Comparative Study To Assess Their Impact On Reopening Due To Postoperative Bleeding
}

\author{
Pratiti Choudhuri ${ }^{1}$, Binay Kumar Biswas ${ }^{1}$
}

\begin{abstract}
BACKGROUND: Open heart surgeries under cardiopulmonary bypass are associated with excessive perioperative bleeding that often requires reoperation. Antifibrinolytics like epsilon aminocaproic acid and tranexamic acid are widely used to control bleeding. There are limited studies primarily showing the impact of these drugs on the incidence of reopening following open heart surgical procedures. The goal of this study was to compare incidence of reopening following open heart surgeries in patients who were administered either epsilon amino caproic acid or tranexamic acid for control of perioperative bleeding. METHODS: A prospective, randomized, controlled trial was performed among seventy-eight patients of either sex in the age group of 18 to 65 years scheduled for open heart surgeries under cardiopulmonary bypass. They were randomly allocated into three groups where group $A(n=26)$ received epsilon aminocaproic acid, group $B(n=26)$ received tranexamic acid and group $C($ control group, $n=26)$ received intravenous $0.9 \%$ normal saline. Patients had similar anaesthetic protocols, and were monitored for twenty-four hours postoperatively to assess reopening rates because of excessive bleeding.

RESULTS: Two patients in each group receiving either tranexamic acid or epsilon aminocaproic acid had excessive bleeding requiring reopening after surgery whereas three patients in the control group had undergone reopening for excessive bleeding (p>0.05).

CONCLUSIONS: Epsilon aminocaproic acid and tranexamic acid exhibit similar and comparable effect to placebo on incidence of reopening for excessive bleeding following open heart surgeries under cardiopulmonary bypass

KEYWORDS: Bleeding, CPB, CABG, antifibrinilytics
\end{abstract}

DOI: http://dx.doi.org/10.4314/ejhs.v25i3.11

\section{INTRODUCTION}

Open heart surgeries involving cardiopulmonary bypass (CPB) are associated with increased life threatening perioperative bleeding that may lead to increased morbidity, mortality, reoperation and administration of excessive blood products (1-3). Apart from surgery itself, different causes of such bleeding include fibrinolysis $(4,5)$ hemodilution $(6,7)$, and others. Antifibrinolytic agents like epsilon aminocaproic acid (EACA) and tranexamic acid (TXA) have been used to reduce bleeding. Studies comparing the efficacy of EACA and TXA in controlling postoperative bleeding reveal inconclusive results (8-11). Moreover, only limited studies are available to show the impact of these two antifibrinolytics on reoperation due to excessive bleeding $(12,13)$. This prospective and comparative study was conducted to find out the relative efficacy of EACA and TXA on post-bypass bleeding affecting the rate of surgical reopening in patients undergoing open heart surgeries under CPB.

\footnotetext{
${ }^{1}$ Department of Anesthesiology, ESI-Postgraduate Institute of Medical Sciences \& Research, Kolkata, India Corresponding Author: Binay Kumar Biswas: biswas.binaykumar@gmail.com
} 


\section{MATERIALS AND METHODS}

After duly approved by the Institutional Ethics Committee (Trial Registration Code: Inst /IEC/ 977/ dated 07.01.2011), this study was carried out in the Cardiothoracic \& Vascular operation theatre complex of the Institute of Postgraduate Medical Education \& Research (IPGME\&R) in Kolkata under West Bengal University of Health Sciences, India, during the period from February 2011 to April 2012. Following written and informed consents, seventy-eight patients from either sex in the age group of 18 to 65 years and ASA physical status II-IV undergoing elective open heart surgeries under CPB were included in the study. Patients undergoing redo-cardiac surgery, with renal insufficiency (serum creatinine higher than 2 $\mathrm{mg} / \mathrm{dl}$ ), undergoing ant platelet therapy, having haematological disorders or hepatic dysfunctions were excluded from the study.

Patients were administered inhalational general anaesthetics (nitrous oxide, isoflurane) following induction with thiopentone and anaesthesia was maintained with positive pressure ventilation through endotracheal tube with the aid of non-depolarizing neuromuscular blockade. Fentanyl was used as analgesic. Various demographic as well as preoperative physiological and laboratory parameters were recorded for each patient. Before initiation of bypass, $\mathrm{N} 2 \mathrm{O}$ had been withdrawn from inhalational anaesthetics. Enrolled patients were assigned randomly either to group A (EACA group, n=26), B (TXA group, $n=26$ ) and $C$ (control group, $n=26$ ) using random number generators designed in Micro Soft Excel.

Patients in Group A received an intravenous $50 \mathrm{ml}$ of diluted EACA as a loading dose of 100 $\mathrm{mg} / \mathrm{kg}$ body weight before the skin incision, followed by a continuous infusion of $100 \mathrm{ml}$ of diluted EACA at an infusion rate of $10 \mathrm{mg} / \mathrm{kg} /$ hour up to 6 hours postoperatively. Group B received an intravenous $50 \mathrm{ml}$ of diluted TXA as a loading dose of $10 \mathrm{mg} / \mathrm{kg}$ body weight before the skin incision, followed by a continuous infusion of $100 \mathrm{ml}$ of diluted TXA at an infusion rate of $1 \mathrm{mg} / \mathrm{kg} /$ hour up to 6 hours postoperatively. Dilution of the drug was done with $0.9 \%$ normal saline (NS) in both the groups. Patients in Group $\mathrm{C}$ received an intravenous $50 \mathrm{ml}$ of $0.9 \% \mathrm{NS}$ as loading dose before the skin incision, followed by a continuous infusion of $100 \mathrm{ml}$ of $0.9 \% \mathrm{NS}$ up to 6 hours postoperatively.

A moderate hypothermic condition $\left(28^{0}\right.$ $\left.32^{\circ} \mathrm{C}\right)$ was achieved and heparin (300U/kg) intravenously was administered before initiation of $\mathrm{CPB}$. During $\mathrm{CPB}$, activated clotting time (ACT) was maintained higher than 600 seconds. Following completion of surgery, patients were weaned off $\mathrm{CPB}$, and heparin was reversed with intravenous protamine sulphate at dose of $1.3 \mathrm{mg} /$ $100 \mathrm{U}$ heparin. Off bypass, following parameters were checked and corrected whenever required: 1) patients' core body, 2) arterial blood gases (ABG), 3) post CPB coagulation screen: a) platelet Count b) international normalised ratio (INR) c) activated partial thromboplastin time (aPTT) and d) serum fibrinogen levels. Bleeding was defined as excessive if it was greater than $200 \mathrm{ml} /$ hour in the first four hours (14). Off bypass, all patients' temperature was raised above $370 \mathrm{C}$. In case of excessive drainage. the following institutional protocol was followed: ACT was rechecked and if found beyond 120 seconds (15), additional protamine sulphate was given. In case of persistent bleeding after correction of ACT with protamine sulphate, platelet count, INR, aPTT and serum fibrinogen levels were re-determined. Platelet count less than $100,000 / \mathrm{cu} \mathrm{mm}$ was corrected platelets at the dose of $0.1 \mu / \mathrm{kg}$ (16). Patients with prolonged prothrombin time (more than 1.5 times normal) were given fresh frozen plasma (FFP) at the dose of $10 \mathrm{ml} / \mathrm{kg}$ for correction (16). Serum fibrinogen level less than $100 \mathrm{mg} / \mathrm{dl}$ was corrected with cryoprecipitate at the dose of $0.25 \mu / \mathrm{kg}$ (16). Hematocrit less than $25 \%$ was corrected with packed red blood cells (PRBC) transfusion to maintain at $30 \%$.

In case of persistent bleeding even after the above corrective measures, a thromboelastogram was performed to determine abnormalities in clot formation and fibrinolysis, if any, and corrective interventions were applied depending on the results. Patients were monitored for twenty-four hours postoperatively to assess reopening rate for the management of excessive bleeding.

At any point of time, if a surgically correctable bleed was suspected, the patient was taken for emergency re-exploration and dropped from the study. If no surgically correctable bleeding was detected on re-exploration, it was 
marked as a case of excessive post $\mathrm{CPB}$ bleeding due to coagulation disorder.

Statistical analyses: Sample size was calculated on the basis of total blood loss in 24 hours period following bypass surgery. It was estimated that 26 subjects would be required per group in order to detect a difference of $200 \mathrm{ml}$ in blood loss between groups with $80 \%$ power and $5 \%$ probability of type-I error (17). Numerical variables of data were compared between groups by one way analysis of variance followed by Bonferroni's test as post-hoc test to establish any difference between the groups. Categorical data were compared between groups by Chi-Square test or Fisher's exact test as appropriate. All analyses were two-tailed and $\mathrm{p}$ value $<0.05$ was considered as statistically significant.

\section{RESULTS}

All the seventy-eight patients fulfilled the inclusion criteria for data collection. They had comparable demographic profiles; there were no significant differences in parameters related to time of aortic cross clamping $(\mathrm{AxCl})$ and $\mathrm{CPB}$ among the groups (Table 1). Preoperative (Table 2) and postoperative (Table 3 ) coagulation profiles (platelet count, INR, activated partial thromboplastin time, serum fibrinogen levels and ACT) were also comparable among the groups.

Table 1: Comparison of demographic profile, types of surgeries and $\mathrm{AxCl}$ and $\mathrm{CPB}$ times

\begin{tabular}{lllll}
\hline Parameters & Gr A $(\mathrm{n}=26)$ & Gr B $(\mathrm{n}=26)$ & Gr C $(\mathrm{n}=26)$ & p value \\
\hline Age (yrs) [Mean+/-SD] & $33.08 \pm 11.27$ & $35.58 \pm 12.07$ & $39.04 \pm 13.15$ & $>0.05$ \\
Body weight (KGs) [Mean+/-SD] & $52.81 \pm 9.72$ & $48.62 \pm 8.07$ & $51.27 \pm 4.04$ & $>0.05$ \\
Height (CMs) [Mean+/-SD] & $159.58 \pm 7.79$ & $158.5 \pm 8.84$ & $156.46 \pm 7.73$ & $>0.05$ \\
Sex (M:F) & $15: 11$ & $14: 12$ & $14: 12$ & $>0.05$ \\
Types of surgeries (ASD:AVR:MVR) & $9: 5: 12$ & $4: 8: 14$ & $6: 7: 13$ & $>0.05$ \\
AxCl time (Sec) [Mean+/-SD] & $44.96 \pm 17.14$ & $48.88 \pm 11.04$ & $48.73 \pm 12.3$ & $>0.05$ \\
CPB time (Sec) [Mean+/-SD] & $72.27 \pm 17.72$ & $74.5 \pm 7.06$ & $76.23 \pm 12.61$ & $>0.05$ \\
\hline
\end{tabular}

* ASD : Atrial septal defect, AVR : Aortic valve replacement, MVR : Mitral valve replacement.

Table 2: Comparison of preoperative coagulation profiles of the patients

\begin{tabular}{lcccr}
\hline Parameters (Mean +/-SD) & Gr A $(\mathrm{n}=26)$ & Gr B $(\mathrm{n}=26)$ & Gr C $(\mathrm{n}=26)$ & $\mathrm{p}$ value \\
\hline Preop platelet $\left(\mathrm{lakh} / \mathrm{mm}^{3}\right)$ & $2.55 \pm 0.88$ & $2.61 \pm 0.77$ & $2.62 \pm 0.85$ & $>0.05$ \\
INR & $1.07 \pm 0.12$ & $1.11 \pm 0.10$ & $1.11 \pm 0.11$ & $>0.05$ \\
APTT $(\mathrm{sec})$ & $29.9 \pm 4.06$ & $30.6 \pm 3.98$ & $30.53 \pm 3.92$ & $>0.05$ \\
Fibrinogen $(\mathrm{mg} / \mathrm{dl})$ & $164.9 \pm 5.47$ & $165.4 \pm 5.98$ & $165.59 \pm 6.87$ & $>0.05$ \\
& & & & \\
Pre heparin ACT $(\mathrm{sec})$ & $108.88 \pm 8.95$ & $105.92 \pm 10.78$ & $108.5 \pm 7.74$ & $>0.05$ \\
\hline
\end{tabular}

Table 3: Comparison of postoperative coagulation profiles of the patients.

\begin{tabular}{lcccc}
\hline Parameters (Mean +/-SD) & Gr A $(\mathrm{n}=26)$ & Gr B $(\mathrm{n}=26)$ & Gr C $(\mathrm{n}=26)$ & p value \\
& & & & \\
\hline Platelet (lakh/mm $\left./ \mathrm{mm}^{3}\right)$ & $2.12 \pm 0.82$ & $2.28 \pm 0.93$ & $2.03 \pm 1.07$ & $>0.05$ \\
INR & $1.14 \pm 0.16$ & $1.17 \pm 0.15$ & $1.14 \pm 0.08$ & $>0.05$ \\
aPTT (seconds) & $30.78 \pm 4.37$ & $32.84 \pm 6.56$ & $33.95 \pm 7.51$ & $>0.05$ \\
Fibrinogen (mg/dl) & $168.44 \pm 8.81$ & $168.83 \pm 9.27$ & $168.81 \pm 8.36$ & $>0.05$ \\
ACT (seconds) & $114.88 \pm 9.76$ & $114.69 \pm 8.86$ & $119.27 \pm 8.48$ & $>0.05$ \\
\hline
\end{tabular}


Two patients each in groups receiving either tranexamic acid or epsilon aminocaproic acid (2/26) had excessive bleeding requiring reopening after surgery whereas it was in three patients out of 26 in control group. The differences among the groups were comparable and statistically insignificant $(\mathrm{p}>0.05)$.

\section{DISCUSSION}

Open heart surgeries under $\mathrm{CPB}$ are frequently associated with life threatening postoperative bleeding often requiring reopening (with its inherent risk of increased mortality and morbidity) to manage this complication $(18,19)$. Persistent bleeding following CPB depends on many factors. The causes of excessive bleeding include fibrinolysis, platelet dysfunction in the form of thrombocytopenia and /or functional alteration of platelet (20), heparin rebound (21), hypothermia (22) and many more.

Fibrinolysis is one of the important factors that are primarily responsible for the hemostatic dysfunction induced by CPB (23). The CPB circuit contains a large surface of thrombogenic material (24). Thrombin activation results in fibrinolytic activity. Plasminogen activator concentrations rise during $\mathrm{CPB}$, but levels of Plasminogen activator inhibitor-1 (PAI-1) remains unaltered (24). Antifibrinolytic agents reduce bleeding by inhibiting fibrinolytic pathway. Being a lysine analogue and antifibrinolytic agents bind competitively to the lysine binding sites on plasminogen and plasmin, inhibiting the interaction with fibrin. Thus, fibrin fails to degrade into fibrin degradation products. The proteolytic action of plasmin is also inhibited (25).

Studies showed effectiveness of antifibrinolytic drugs in reducing perioperative bleeding and transfusion requirements $(25,26)$. However, limited trials are available to demonstrate the impact of these two antifibrinolytic agents on reopening rate (13). Our study reveals that administration of either TXA or EACA during open heart surgical procedures under $\mathrm{CPB}$ has similar outcome on reopening rate as compared to placebo. Chauhan et al had found both these antifibrinolytic agents could reduce reopening rates when compared to placebo following coronary artery bypass grafting $(\mathrm{CABG})$ surgery under $\mathrm{CPB}$ (11). Unlike our study, patients exclusively undergoing $\mathrm{CABG}$ were included in their research work. Often, patients undergoing $\mathrm{CABG}$ are treated with preoperative antiplatelet medications. Studies showed that antiplatelet medication (aspirin) impairs secondary hemostasis and thrombus stability by acetylating fibrinogen and enhancing fibrinolysis $(27,28)$. Hence, antifibrinolytic agents may be more helpful in reducing bleeding in patients receiving antiplatelet therapy. Our patients did not receive pre-operative anti-platelet therapy eliminating source of bias from this issue. The difference in result in our study as compared to that of Chauhan et al partly may be because of anti-platelet therapy and partly may be CABG operation with unidentified factors which can be further established by future similarly designed studies.

Set of our research work, profile of operating surgeons and study population were uniform in nature. The research was carried out in a postdoctoral working unit with consistent team of surgeons working in the same set up for more than 4 years. Our study population made a cohort of surgical patients undergoing ASD/MVR/AVR operations and no one had undergone CABG surgery. Relative numbers of patients under each category of surgical procedures were comparable (Table-1). Duration of bypass and age of patients undergoing surgery are factors for increased risk of bleeding following CPB $(29,30)$. Tetty et al have demonstrated that though duration of bypass increases post CPB bleeding, difference in the amount of bleeding following 1, 2 or 3 hour of bypass is clinically acceptable with no statistical significance (29). Duration of CPB in our study was comparable among the groups, since it was between 60 to 90 minutes which seems reasonable for cardiac surgical procedures (Table 1). Therefore, it seems that CPB time did not play any confounding impact on our results. Similarly, age of patients was also comparable among the groups without placing any biased impact on outcome of our study. Task force formed by Society of Cardiovasular Surgeons and Society of Cardiac Anesthesiologist has highlighted that advanced age ( $>70$ years) contributes to higher post CPB bleeding (30). We included patients aged upto 65 years, and most of our patients were aged below 50 years eliminating the impact of age on postbypass bleeding in our study (Table1). 
Klaus et al in 2011 analysed perioperative data of 234 paediatric patients (114 patients receiving TXA in first five months and 120 patients receiving EACA in second five months) weighing less than $20 \mathrm{~kg}$, who had undergone cardiac surgery. They found that both TXA and EACA were comparable in their effect on reoperation (31). While assessing the amount of chest tube drainage following administration of TXA, Santos et al found their results comparable to that of placebo group in terms of reopening rate (12). The finding_of our study are also similar with that of a recent study done by Henry et al. (13). They had found that both TXA and EACA could not decrease the risk of reoperation significantly. Based on evidences from existing studies and the findings of our study, it can be hypothesized that besides fibrinolysis, platelet dysfunction and other factors may also play a huge role in post $\mathrm{CPB}$ hemostatic defects $(11-13,31)$.

We re-emphasize that our study had followed reasonably uniform methods and results, and thus, have the least possible bias from various possible confounding factors. However, future studies will definitely provide further data paving more avenues for critical comparison and analysis of our results. In conclusion, the results of our study show that prophylactic administration of either EACA or TXA during cardiac surgeries performed under $\mathrm{CPB}$ has insignificant effect on the rate of re-exploration because of excessive bleeding.

\section{REFERENCES}

1. Sellman M, Intonti MA, Ivert T. Reoperations for bleeding after coronary artery bypass procedures during 25 years. Eur $J$ Cardiothorac Surg 1997; 11: 521-7.

2. Ottino G, De Paulis R, Pansini S, et al. Major sternal wound infection after open heart surgery: a multivariate analysis of risk factors in 2,579 consecutive operative procedures. Ann Thorac Surg 1987; 44: 173-9.

3. Moulton MJ, Creswell LL, Mackey ME, Cox JL, Rosenbloom M. Reexploration for bleeding is a risk factor for adverse outcomes after cardiac operations. J Thorac Cardiovasc Surg 1996; 111(5): 1037-46.

4. Tice DA, Reed GE, Clauss RH, Worth MH. Hemorrhage due to fibrinolysis occurring with open-heart operations. $J$ Thorac Cardiovas Surg 1963; 46: 673.
5. Moriau M, Masure R, Hurlet A, et al. Haemostasis disorders in open heart surgery with extracorporeal circulation. Vox Sang 1977; 32: 41.

6. Harker L, Malpass TW, Branson HE, Hessel II EA, Slichter SA. Mechanism of abnormal bleeding in patients undergoing cardiopulmonary bypass: Acquired transient platelet dysfunction associated with selective a-granule release. Blood 1980; 56: 824.

7. Brody JI, Pickering NJ, Fink GB. Concentrations of factor VIII-related antigen and factor XIII during open heart surgery. Transfusion 1986; 26: 478.

8. Verma K, Errico TJ, Vaz KM, Lonner BS. A prospective, randomized, double-blinded single-site control study comparing blood loss prevention of tranexamic acid (TXA) to epsilon aminocaproic acid (EACA) for corrective spinal surgery. BMC Surg 2010; 10: 10-3.

9. Pinosky ML, Kennedy DJ, Fishman RL, et al. Tranexamic Acid Reduces Bleeding After Cardiopulmonary Bypass When Compared to Epsilon Aminocaproic Acid and Placebo. J Card Surg 1997; 12: 330-8.

10. Maineri P, Covaia G, Realini M, et al. Postoperative bleeding after coronary revascularization. Comparison between tranexamic acid and epsilon-aminocaproic acid. Minerva Cardioangiol 2000; 48: 155-60.

11. Chauhan S, Parag G, Akshay B, Kale S, Usha K. A Comparison of aminocaproic Acid and Tranexamic Acid in Adult Cardiac Surgery. Annals of Cardiac Anaesthesia 2004; 7: 40-3.

12. Santos ATL, Kalil RAK, Bauemann C, Pereira JB, Nesralla IA. A randomized, double-blind, and placebo-controlled study with tranexamic acid of bleeding and fibrinolytic activity after primary coronary artery bypass grafting. Braz J Med Biol Res 2006; 39: 63-9.

13. Henry DA, Carless PA, Moxey AJ, et al. Antifibrinolytic use for minimising perioperative allogeneic blood transfusion. Cochrane Database Syst Rev 2011; 3: CD001886.

14. Timothy SH, Brevetti GR, Skoultchi AJ, Sines JC, Gregory P, Spotnitz AJ. Re-exploration for Hemorrhage Following Open Heart Surgery Differentiation on the Causes of Bleeding and the Impact on Patient Outcomes. Ann Thorac Cardiovasc Surg 2001; 7: 352-7. 
15. Shore-Lesserson L. Coagulation Monitoring. In: Kaplan JA, Reich DL, Lake CL, Konstadt SN, eds. Kaplan's Cardiac Anesthesia. 5th ed. Philadelphia: Saunders Elsevier, 2006: 558-9.

16. Milas B, Johes D, Gorman R. Management of bleeding and coagulopathy after heart surgery. Semin Thorac Cardiovasc Surg 2000; 12: 326.

17. Roderick W, Landymore, J, Thomas M, Heather L, Cheryl C. The use of low-dose aprotinin, e-aminocaproic acid or tranexamic acid for prevention of mediastinal bleeding in patients receiving aspirin before coronary artery bypass operations. Eur J Cardiothorac Surg 1997; 11: 798-800.

18. Yavus S, Eris C, Turk T. Re-exploration for excessive bleeding after coronary artery bypass surgery: how early is better? Eur $J$ Cardiothorac Surg 2007; 32: 819-20.

19. P. Wauthy, J. P. Goldstein, H. Demanet, F. E. Deuvaert. Redo Valve Surgery Nowadays: What Have we Learned? Acta Chir Belg 2003; 103: 475-80.

20. Harker LA, Malpass TW, Branson HE. Mechanism of abnormal bleeding in patients undergoing cardiopulmonary bypass: Acquired transient platelet dysfunction associated with selective $\infty$-granule release. Blood 1980; 56: 824.

21. Frick PG, Brogli H. The mechanism of heparin rebound after extracorporeal circulation for open cardiac surgery. Surgery 1966; 59: 721.

22. Valeri CR, Khabbaz K, Khuri SF, et al. Effect of skin temperature on platelet function in patients undergoing bypass. $J$ Thorac Cardiovasc Surg 1992; 104: 108.

23. Khuri SF, Michelson AD, Valeri CR. The effect of cardiopulmonary bypass on hemostasis and coagulation. In: Loscalzo J, Schafer AI, eds. Thrombosis and hemorrhage.
Cambridge,MA: Blackwell Scientific, 1994: 1051-73.

24. Spiess BD., Horrow J, Kaplan JA. Transfusion medicine and coagulation disorders. In : Kaplan JA., Reich DL., Lake CL., Konstadt SN, eds. Kaplan's Cardiac Anaesthesia. 5th ed. Philadelphia: Elsevier Saunders, 2006: 967-73.

25. DelRossi AJ, Cernaianu AC, Botros S, Lemole GM, Moore R. Prophylactic treatment of postperfusion bleeding using EACA. Chest 1989; 96: 27-30.

26. Rousou JA, Engelman RM, Flack JE 3rd, Deaton DW, Owen SG. Tranexamic acid significantly reduces blood loss associated with coronary revascularization. Ann Thorac Surg 1995; 59: 671-5.

27. Bjornsson TD, Schneider DE, Berger H, Jr. Aspirin acetylates fibrinogen and enhances fibrinolysis. Fibrinolytic effect is independent of changes in plasminogen activator levels. $J$ Pharmacol Exp Ther 1989; 250: 154-61.

28. Moroz LA. Increased blood fibrinolytic activity after aspirin ingestion. $N$ Engl $\mathrm{J}$ Med 1977; 296: 525-9.

29. Tettey M, Aniteye E, Sereboe L, et al. Predictors of Post Operative Bleeding and Blood Transfusion in Cardiac Surgery. Ghana Med J 2009; 43: 71-6.

30. Spiess BD, Shore-Lesserson L, StaffordSmith M, et al. Perioperative blood transfusion and blood conservation in cardiac surgery: the Society of Thoracic Surgeons and The Society of Cardiovascular Anesthesiologists clinical practice guideline. Ann Thorac Surg 2007 ; 83: S27-86.

31. Klaus MTB, Ralph GAH, Christian S, et al. Tranexamic acid versus Epsilon-aminocaproic acid: efficacy and safety in paediatric cardiac surgery. Eur J Cardiothorac Surg 2011; 39: 892-7. 